\title{
The impact of clinical and genetic factors on ticagrelor and clopidogrel antiplatelet therapy
}

\begin{abstract}
Aim: To determine clinically significant factors which may alter the effect of dual antiplatelet therapy with aspirin and ticagrelor or clopidogrel in patients who had undergone percutaneous coronary intervention and stent implantation. Materials \& methods: The study included 378 patients. All the patients had undergone percutaneous coronary intervention and stent implantation. Platelet aggregation and genotyping for CYP2C19 *2 (rs4244285) and CYP4F2 (rs2108622, rs1558139, rs3093135 and rs2074902) was performed. Results: Significantly lower platelet aggregation values $(\%$ agr $)$ were detected in ticagrelor users who carried CYP4F2 rs3093135 TT variant $(14.67 \pm 5.07 \%$ arr $)$ versus AA $(22.88 \pm 6.30 \%$ arr $), p=0.0004$, or AT (20.56 \pm $6.51 \%$ arr $), p=0.0126$. Conclusion: Results of the current study showed that CYP4F2 rs3093135 TT variant carriers had a higher antiplatelet effect of ticagrelor, and more frequently had nonprocedural bleeding during ticagrelor therapy, as compared with AA and AT variant carriers.
\end{abstract}

First draft submitted: 12 April 2017; Accepted for publication; 4 May 2017; Published online: 12 June 2017

Keywords: clopidogrel therapy $\bullet$ STEMl $\bullet$ ticagrelor pharmacogenomics

Dual antiplatelet therapy (DAPT) with aspirin and ADP receptor blocker (ticagrelor, prasugrel or clopidogrel) is recommended for the secondary prevention of ischemic complications in patients with acute coronary syndromes, following percutaneous coronary intervention (PCI) and stent implantation. In large trials, prasugrel and ticagrelor have showed superior therapeutic effect compared with clopidogrel. Prasugrel reduced primary end point (cardiovascular death, nonfatal myocardial infarction (MI) or stroke) in the Trial to Assess Improvement in Therapeutic Outcomes by Optimizing Platelet InhibitionThrombolysis In Myocardial Infarction 38 [1]. Ticagrelor was shown to reduce primary end point in the Platelet Inhibition and Patient Outcomes (PLATO) trial [2]. Thus, the European Society of Cardiology issued guidelines for the diagnosis and treatment of ST-elevation myocardial infarction (STEMI) [3], non-STEMI (NSTEMI) [4] and myocardial revascularization [5]. According to these guidelines, ticagrelor or prasugrel is now preferred over clopidogrel due to their increased antiplatelet activity and lower risk of vascular thrombotic events. However, ticagrelor or prasugrel may cause higher incidence of nonprocedural noncoronary artery bypass grafting bleeding $[1,2,6]$.

Clopidogrel, a key antagonist of platelet ADP receptors, has been in use over the past two decades. This prodrug is metabolized by two main competing pathways. The major one is via human hepatic carboxylesterase 1 , which hydrolyze clopidogrel into inactive clopidogrel acid metabolite. The minor one consists of two CYP450-dependent steps [7,8]. During the first step, clopidogrel is metabolized into a thiolactone (2-oxo-clopidogrel) by CYP1A2, CYP2B6 and CYP2C19. The second step involves CYP2B6, CYP2C9, CYP2C19 and CYP3A4, which forms active thiol-containing metabolite [7]. In total,
Vacis Tatarunas ${ }^{* 1}$, Nora Kupstyte ${ }^{2}$, Remigijus Zaliunas $^{2}$, Agne Giedraitiene ${ }^{3}$ \& Vaiva Lesauskaite ${ }^{1}$ ${ }^{1}$ Institute of Cardiology, Lithuanian University of Health Sciences, Sukileliu 17, Kaunas LT 50009, Lithuania 2Department of Cardiology, Lithuanian University of Health Sciences, Eiveniu 2, Kaunas LT 50009, Lithuania ${ }^{3}$ Department of Microbiology, Lithuanian University of Health Sciences, A. Mickeviciaus 9, Kaunas LT 44307, Lithuania

*Author for correspondence: Tel.: +37063868251 Fax: +370 37302872 vacis.tatarunas@lsmuni.lt
Future
Medicine $\mathrm{fS}$ par of 
nearly $85 \%$ of clopidogrel is transformed into nonactive substances [9]. Only the active form of clopidogrel can inhibit platelet aggregation by binding irreversibly to the platelet ADP (P2Y12) receptors. Currently, the CYP2C19 enzyme is the main enzyme which takes a part in the bioactivation of 2-oxoclopidogrel [10]; studies with the CYP2C19 inhibitor omeprazole have confirmed this fact. Research has also shown that users of clopidogrel and omeprazole experienced a lower antiplatelet effect of clopidogrel than nonusers of omeprazole [11]. The other enzyme, CYP3A4/A5, was found to be involved in the pathway of clopidogrel bioactivation in enterocytes. von Beckerath et al. determined that the concentration of clopidogrel's active metabolite in patients with gastrectomy and small bowel loss is about 50-times lower than that in patients with an intact gastrointestinal system [12]. In addition, other factors such as $\mathrm{ABCB} 1$ and PON1 were found to be associated with a reduced antiplatelet effect of this drug [13,14]. However, no significant effect of PON1 was shown by other authors [15-18]. While it is known that some genetic (CYP2C19, CYP3A5, ABCB1 and PON1), drug, dietary and lifestyle factors affect clopidogrel metabolism, other factors which might increase the risk of adverse cardiovascular events in clopidogrel users are yet to be clarified [19].

Compared with clopidogrel, ticagrelor is a newer generation cyclopentyl triazolo-pyrimidine antiplatelet drug that demonstrates a faster onset, more potent inhibition and a reversible antiplatelet effect. Ticagrelor directly acts on platelets by reversibly blocking platelet surface membrane P2Y12 (ADP) receptors, with no need for metabolic activation. However, the most recent study on ticagrelor metabolism showed that ticagrelor may act irreversibly by altering P2Y12 receptor conformation, or by staying bound to this receptor [20]. It is known that ticagrelor is metabolized by hepatic CYP3A4/3A5 enzymes, which may reduce the antiplatelet effect of ticagrelor [21]. Three gene loci, SLCO1B1 (rs113681054), UGT2B7 (rs61361928) and CYP3A4 (rs62471956 and rs56324128), were shown to be associated with ticagrelor or its metabolite concentrations in blood plasma [22]. However, these variants had no associations with cardiovascular death, MI, stroke, noncoronary artery bypass grafting-related bleeds or dyspnea [22]. It is worth noting that SLCO1B1 rs113681054 and rs4149056, CYP3A4 rs2242480 and CYP3A5 rs776746 had no significant

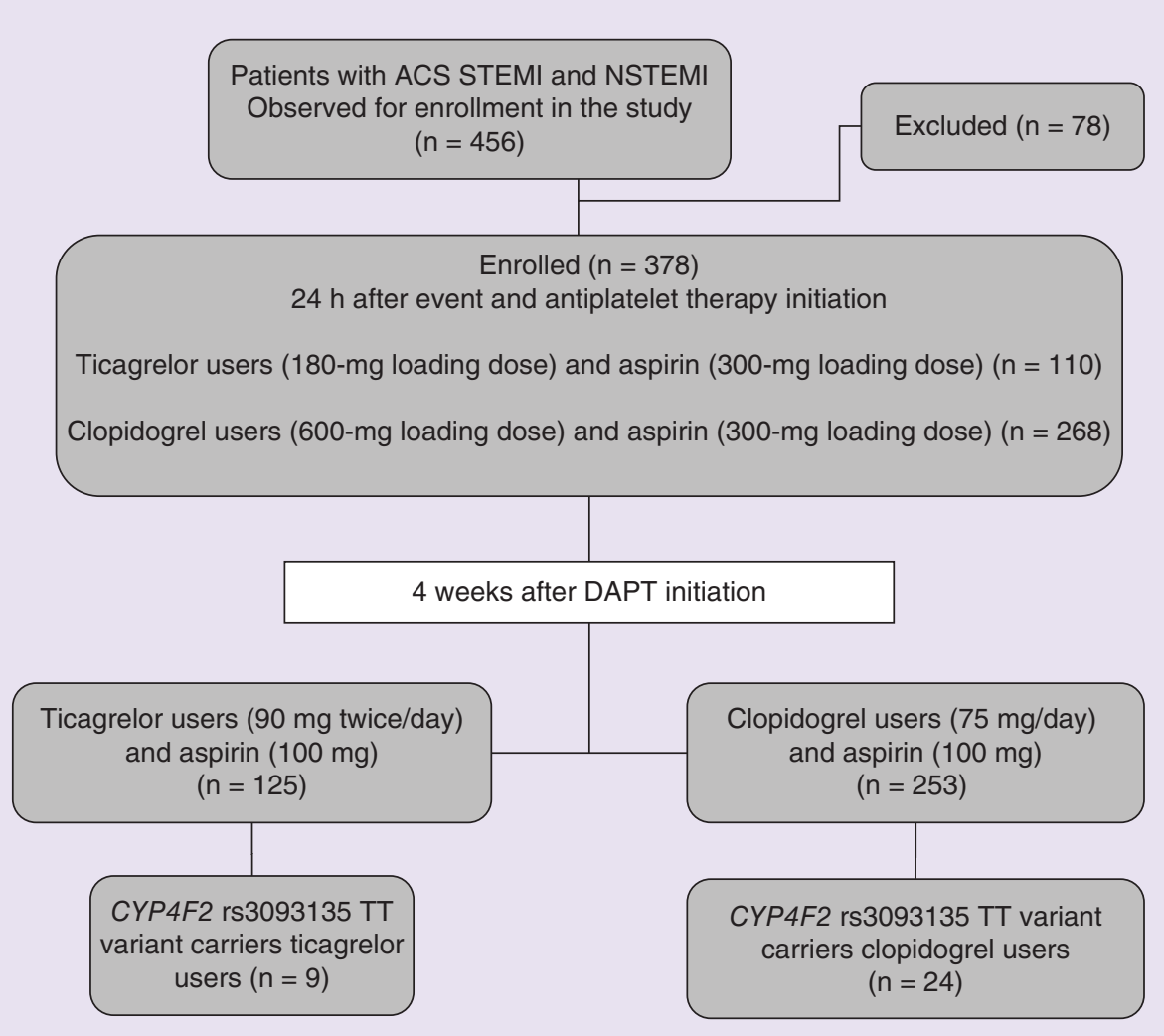

Figure 1. Study design diagram.

ACS: Acute coronary syndrome; DAPT: Dual antiplatelet therapy; NSTEMI: Non-ST-elevation myocardial infarction; STEMI: ST-elevation myocardial infarction. 
Table 1. Comparison of antiplatelet effect in ticagrelor and clopidogrel using patients during induction and after 4 weeks of treatment.

\begin{tabular}{|c|c|c|c|c|}
\hline \multirow[t]{2}{*}{ Antiplatelet drug } & \multicolumn{2}{|r|}{ During induction } & \multicolumn{2}{|c|}{ After 4 weeks of treatment } \\
\hline & n (\%) & $\begin{array}{l}\text { Platelet aggregation } \\
\text { values, mean } \pm \text { SD } \% \text { agr }\end{array}$ & n (\%) & $\begin{array}{l}\text { Platelet aggregation values, } \\
\text { mean } \pm \text { SD } \% \text { agr }\end{array}$ \\
\hline Ticagrelor & $110(29.1)$ & $20.64 \pm 10.68$ & $125(33.1)$ & $21.32 \pm 6.63$ \\
\hline Clopidogrel & $268(70.9)$ & $35.20 \pm 12.76$ & $253(66.9)$ & $41.06 \pm 10.84$ \\
\hline Total & $378(100.0)$ & $30.96 \pm 13.86$ & $378(100.0)$ & $34.53 \pm 13.40$ \\
\hline
\end{tabular}

effect on pharmacokinetics and pharmacodynamics of ticagrelor [23]. Thus, currently there are no genetic polymorphisms identified which may explain the antiplatelet activity of ticagrelor.

The aim of this study was to determine clinically significant factors which may alter the effect of DAPT with aspirin and ticagrelor or clopidogrel in patients who have undergone PCI and stent implantation.

\section{Materials \& methods}

\section{Study population \& inclusion criteria}

Totally 378 patients were enrolled into the study (Figure 1). All the patients had undergone PCI and stent implantation at the Department of Cardiology at the Hospital of the Lithuanian University of Health Sciences (LSMU), Kauno klinikos, Lithuania. All the patients were treated with DAPT of ticagrelor or clopidogrel and aspirin between January 2013 and December 2016. They used DAPT for at least 4 weeks after initiation of the therapy. More detailed clinical characteristics are presented in Tables 1 \& 2 .

\section{Exclusion criteria}

Exclusion criteria were conditions leading to increased activity of coagulation (malignant neoplasia and severe inflammation [C-reactive protein level $>100 \mathrm{mg} / \mathrm{l}$ ] or patients who had undergone antibiotic therapy due to infection), cardiogenic shock or hypovolemia and the refusal of a patient to take part in this study.

\section{Patient clinical data \& blood specimen collection}

Clinical data were collected from patient medical reports. A loading dose of ticagrelor $(180 \mathrm{mg})$ or clopidogrel $(600 \mathrm{mg})$ was administered to patients in combination with aspirin $(300 \mathrm{mg})$. Four weeks after DAPT induction, the patients were administered ticagrelor $(90 \mathrm{mg}$ twice a day) or clopidogrel $(75 \mathrm{mg}$ per day) in combination with a fixed $100 \mathrm{mg}$ per day dose of aspirin (Figure 1). All these patients were treated with lipid-lowering drugs (statins), ACE inhibitors (or angiotensin receptor II blockers) and $\beta$-adrenoblockers.
Atorvastatin was prescribed to $98 \%$ of the patients receiving statin therapy. Rosuvastatin and simvastatin were prescribed to $2 \%$ of statin users. Blood samples for platelet aggregation and DNA extraction were collected twice; on the next morning after antiplatelet therapy initiation, and 4 weeks after DAPT induction.

About 6 months after antiplatelet treatment initiation, patients with CYP4F2 rs3093135 TT variant (Figure 1) were asked if bleeding, such as a nosebleed, hematomas, blood in urine, gastrointestinal bleeding or thrombosis, had occurred. Rehospitalization due to thrombosis (recurrent MI or stroke) was also reported. Bleeding was defined according to Bleeding Academic Research Consortium classification [24].

\section{Platelet aggregation}

A platelet aggregation test was performed at the certified Laboratory of Molecular Cardiology, Institute of Cardiology, Lithuanian University of Health Sciences, Kaunas, Lithuania. The platelet aggregation test was performed according to the classical Born method using ChronoLog 490-2D platelet aggregometer (Chrono-Log, PA, USA). Platelet aggregation was measured in platelet-rich and in platelet-poor plasma by comparing the intensity of light transmission. Preparation of platelet-rich plasma was performed by centrifuging the whole blood at $100 \times g$ for $15 \mathrm{~min}$. Preparation of platelet-poor plasma was performed by centrifuging the platelet-rich plasma at 1000 $\times g$ for $30 \mathrm{~min}$. Transmission of light in the platelet-poor plasma was considered $100 \%$, and platelet aggregation was expressed as \%agr. Platelet aggregation after induction with $\mathrm{ADP}$ (final concentration, $5 \mu \mathrm{M}$; Chrono-Log) was determined as previously described [25].

\section{Genotype detection}

Genotyping procedures were done at the certified Laboratory of Molecular Cardiology, Institute of Cardiology, Lithuanian University of Health Sciences, Kaunas, Lithuania. The residual buffy coat of the citrated blood sample, which was left after platelet aggregation, was further used for DNA extraction using the salting-out method. The standard manufacturer's protocol for CYP2C19 
Research Article Tatarunas, Kupstyte, Giedraitiene \& Lesauskaite

Table 2. The effect of clinical factors on antiplatelet effect of ticagrelor and clopidogrel after 4 weeks of treatment.

Variable

Ticagrelor users

Clopidogrel users

n (\%) Platelet aggregation with p-value $n(\%) \quad$ Platelet aggregation with $\quad$-value
$A D P$, mean $\pm S D \%$ agr

ADP, mean \pm SD \% agr

Gender:

Women

$98(78.4) \quad 20.94 \pm 6.62$

0.222

$174(68.8) \quad 40.61 \pm 11.24$

0.324

Patient age:

Under 65 years

$27(21.6) \quad 22.70 \pm 6.60$

$79(31.2) \quad 42.06 \pm 9.89$

65 years and older $54(43.2) \quad 21.48 \pm 5.92$

$0.813 \quad 100(39.5) \quad 40.50 \pm 11.64$

0.505

Smoking habit:

Nonsmokers

$90(72) \quad 20.87 \pm 6.16$

0.09

$183(72.3) \quad 41.33 \pm 10.51$

0.523

Smokers

$35(28) \quad 23.09 \pm 7.21$

70 (27.7)

$40.36 \pm 11.71$

Diabetes ${ }^{\dagger}$ :

Present

28 (22.4) $23.14 \pm 5.54$

0.09

$63(24.9) \quad 40.78 \pm 12.77$

0.81

Absent

$97(77.6) \quad 20.79 \pm 6.85$

$190(75.1) \quad 41.16 \pm 10.16$

ST segment elevation ${ }^{\ddagger}$ :

$\begin{array}{lll} & 46(36.8) & 21.02 \pm 6.50\end{array}$

$0.7 \quad 80(31.6) \quad 43.12 \pm 9.64$

0.04

Non-STEM

$79(63.2) \quad 21.49 \pm 6.74$

$173(68.4) \quad 40.11 \pm 11.25$

ACE inhibitor:

Users

$94(75.2) \quad 20.45 \pm 6.30$

0.01

$207(81.8) \quad 40.84 \pm 11.35$

0.69

Nonusers

$31(24.8) \quad 23.97 \pm 7.00$

$46(18.2)$

$41.63 \pm 11.24$

Amiodarone:

Users

$2(1.6)$

$14.5 \pm 6.36$

0.14

$5(2)$

$48.80 \pm 5.45$

Nonusers

$123(98.4) \quad 21.43 \pm 6.60$

$248(98)$

$40.91 \pm 10.87$

Amlodipine:

Users

$5(4)$

$18.60 \pm 4.98$

0.35

$11(4.3)$

$40.18 \pm 10.68$

Nonusers

$120(96) \quad 21.43 \pm 6.68$

$242(95.7)$

$41.10 \pm 10.87$

Angiotensin receptor II blocker:

\begin{tabular}{|c|c|c|c|c|c|c|}
\hline Users & $7(5.6)$ & $20.86 \pm 8.07$ & 0.85 & $23(9.1)$ & $39.78 \pm 9.92$ & 0.55 \\
\hline Nonusers & $118(94.4)$ & $21.35 \pm 6.57$ & & $230(90.9)$ & $41.19 \pm 10.94$ & \\
\hline \multicolumn{7}{|l|}{$\beta$-blocker: } \\
\hline Users & $104(83.2)$ & $20.83 \pm 6.34$ & 0.06 & $224(88.5)$ & $41.34 \pm 11.32$ & 0.25 \\
\hline Nonusers & $21(16.8)$ & $23.76 \pm 7.62$ & & 29 (11.5) & $38.90 \pm 10.77$ & \\
\hline \multicolumn{7}{|l|}{ Gliclazide: } \\
\hline Users & $3(2.4)$ & $26.67 \pm 2.08$ & 0.15 & $14(5.5)$ & $40.71 \pm 10.00$ & 0.9 \\
\hline Nonusers & 122 (97.6) & $21.19 \pm 6.65$ & & $239(94.5)$ & $41.08 \pm 10.91$ & \\
\hline
\end{tabular}


Table 2. The effect of clinical factors on antiplatelet effect of ticagrelor and clopidogrel after 4 weeks of treatment (cont.).

\begin{tabular}{|c|c|c|c|c|c|c|}
\hline \multirow[t]{2}{*}{ Variable } & \multicolumn{3}{|c|}{ Ticagrelor users } & \multicolumn{3}{|c|}{ Clopidogrel users } \\
\hline & n (\%) & $\begin{array}{l}\text { Platelet aggregation with } \\
\text { ADP, mean } \pm \text { SD } \% \text { agr }\end{array}$ & p-value & n (\%) & $\begin{array}{l}\text { Platelet aggregation with } \\
\text { ADP, mean } \pm S D \% \text { agr }\end{array}$ & $p$-value \\
\hline \multicolumn{7}{|c|}{ Glimepiride: } \\
\hline Users & 0 & - & - & $3(1.2)$ & $57.67 \pm 6.11$ & 0.007 \\
\hline Nonusers & $125(100)$ & $21.32 \pm 6.63$ & & $250(98.8)$ & $40.86 \pm 10.74$ & \\
\hline \multicolumn{7}{|l|}{ Ivabradin: } \\
\hline Users & $16(12.8)$ & $23.63 \pm 6.21$ & 0.13 & $38(15)$ & $41.42 \pm 10.50$ & 0.82 \\
\hline Nonusers & $109(87.2)$ & $20.98 \pm 6.65$ & & $215(85)$ & $41.00 \pm 10.92$ & \\
\hline \multicolumn{7}{|c|}{ Metformin: } \\
\hline Users & $10(8)$ & $20.60 \pm 6.29$ & 0.12 & $37(14.6)$ & $45.19 \pm 11.51$ & 0.012 \\
\hline Nonusers & $115(92)$ & $21.38 \pm 6.68$ & & $216(85.4)$ & $40.36 \pm 10.59$ & \\
\hline \multicolumn{7}{|c|}{ Pantoprazole: } \\
\hline Users & $13(10.4)$ & $24.15 \pm 5.27$ & 0.104 & $17(6.7)$ & $42.00 \pm 13.59$ & 0.71 \\
\hline Nonusers & $112(89.6)$ & $20.99 \pm 6.71$ & & $236(93.3)$ & $41.00 \pm 10.65$ & \\
\hline \multicolumn{7}{|l|}{ Ranitidine: } \\
\hline Users & $20(16)$ & $19.85 \pm 6.93$ & 0.28 & $40(15.8)$ & $41.58 \pm 10.45$ & 0.74 \\
\hline Nonusers & $105(84)$ & $21.60 \pm 6.57$ & & $213(84.2)$ & $40.97 \pm 10.93$ & \\
\hline \multicolumn{7}{|c|}{ Spironolactone: } \\
\hline Users & $22(17.6)$ & $21.91 \pm 6.33$ & 0.64 & 39 (15.4) & $41.72 \pm 8.92$ & 0.68 \\
\hline Nonusers & $103(82.4)$ & $21.19 \pm 6.71$ & & $214(84.6)$ & $40.94 \pm 11.17$ & \\
\hline \multicolumn{7}{|l|}{ Statin: } \\
\hline Users & $115(92)$ & $21.12 \pm 6.52$ & 0.25 & $221(87.4)$ & $41.47 \pm 10.93$ & 0.12 \\
\hline Nonusers & $10(8)$ & $23.60 \pm 7.82$ & & $32(12.6)$ & $38.28 \pm 9.94$ & \\
\hline \multicolumn{7}{|c|}{ Torasemide: } \\
\hline Users & $21(16.8)$ & $20.67 \pm 7.35$ & 0.62 & $34(13.4)$ & $42.18 \pm 9.55$ & 0.52 \\
\hline Nonusers & $104(83.2)$ & $21.45 \pm 6.51$ & & $219(86.6)$ & $40.89 \pm 11.04$ & \\
\hline \multicolumn{7}{|c|}{ Trimetazidine: } \\
\hline Users & $17(13.6)$ & $21.59 \pm 7.35$ & 0.85 & $13(5.1)$ & $42.23 \pm 12.99$ & 0.69 \\
\hline Nonusers & $108(86.4)$ & $21.28 \pm 6.54$ & & 240 (94.9) & $41.00 \pm 10.74$ & \\
\hline \multicolumn{7}{|c|}{ Verapamil: } \\
\hline Users & $1(0.8)$ & 25.00 & 0.58 & $2(0.8)$ & $43.00 \pm 8.48$ & 0.8 \\
\hline Nonusers & $124(99.2)$ & $21.29 \pm 6.65$ & & $251(99.2)$ & $41.05 \pm 10.87$ & \\
\hline Total & $\begin{array}{l}125 \\
(100.0)\end{array}$ & $21.32 \pm 6.63$ & & $\begin{array}{l}253 \\
(100.0)\end{array}$ & $41.06 \pm 10.84$ & \\
\hline \multicolumn{7}{|c|}{$\begin{array}{l}\text { ACE inhibitor: zofenopril, ramipril, perindopril, noliprel, fosinopril. } \\
\text { Angiotensin receptor II blocker: losartan, valsartan. } \\
\text {-blocker: nebivolol, metoprolol. } \\
\text { Statins: atorvastatin, simvastatin and rosuvastatin. } \\
\text { 'Insulin and noninsulin users. } \\
\text { fCondition during DAPT induction. } \\
\text { ACE: Angiotensin-converting enzyme; DAPT: Dual antiplatelet therapy; NSTEMI: Non-ST-elevation myocardial infarction; SD: Standard deviation; STEMI: ST-elevation } \\
\text { myocardial infarction. }\end{array}$} \\
\hline
\end{tabular}


*2 (rs4244285) and CYP4F2 rs2108622, rs1558139, rs3093135 and rs2074902 was used for genotyping with Taqman probes (Applied Biosystems, MA, USA). Genotyping was performed using an ABI 7900HT fast real-time PCR thermocycler (Applied Biosystems).

\section{Statistical analysis}

Frequencies are presented in percentages. Means are presented as mean \pm standard deviation. Means were analyzed using parametric tests. If the p-value was less than 0.05 , it was regarded as statistically significant.

\section{Results}

Platelet aggregation values with ADP were higher after 4 weeks of treatment with antiplatelets, in comparison with the day after initiation of treatment: $34.53 \pm 13.40$ versus $30.96 \pm 13.86 \%$ agr , respectively, $\mathrm{p}=0.0003$. More detailed analysis revealed that ticagrelor users had lower platelet aggregation values than users of clopidogrel, the day after initiation of treatment and after 4 weeks of treatment (Table 1). A consistent antiplatelet effect was observed in ticagrelor users, the day after treatment initiation and after 4 weeks of treatment, $\mathrm{p}=0.55$. On the contrary, clopidogrel users had higher platelet aggregation values after 4 weeks of treatment, compared with the day after treatment initiation $(41.06 \pm 10.84$ vs $35.20 \pm 12.76 \%$ agr , respectively, $\mathrm{p}<0.0001)$.

\section{The effect of clinical factors on antiplatelet} therapy

The impact of clinical factors on antiplatelet therapy was analyzed in both ticagrelor and clopidogrel users (Table 2). Users of clopidogrel with STEMI $(n=80)$ had higher platelet aggregation values $(43.12 \pm 9.64 \%$ agr $)$ than the non-STEMI patients $(40.11 \pm 11.25 \%$ agr $), \mathrm{p}=0.04$. No such effect was found in ticagrelor users $(p>0.05)$. The patients who were prescribed ticagrelor and ACE

\section{Table 3. The effect of CYP2C19 and CYP4F2 variants on antiplatelet effect of ticagrelor and} clopidogrel after 4 weeks of treatment.

\begin{tabular}{|c|c|c|c|c|c|c|}
\hline \multirow[t]{2}{*}{ Variable } & \multicolumn{3}{|c|}{ Ticagrelor users } & \multicolumn{3}{|c|}{ Clopidogrel users } \\
\hline & n (\%) & $\begin{array}{l}\text { Platelet aggregation with } \\
\text { ADP, mean } \pm \text { SD } \% \text { agr }\end{array}$ & $p$-value & n (\%) & $\begin{array}{l}\text { Platelet aggregation } \\
\text { with } A D P \text {, mean } \pm S D \% \text { agr }\end{array}$ & p-value \\
\hline \multicolumn{7}{|c|}{ CYP2C19: } \\
\hline$* 1 * 1$ & $81(64.8)$ & $20.30 \pm 6.42$ & 0.063 & $218(86.2)$ & $40.15 \pm 10.75$ & 0.002 \\
\hline$* 1 * 2$ & $37(29.6)$ & $23.22 \pm 7.08$ & & $34(13.4)$ & $46.53 \pm 9.80$ & \\
\hline$* 2 * 2$ & $7(5.6)$ & $23.14 \pm 4.29$ & & $1(0.4)$ & 55.00 & \\
\hline \multicolumn{7}{|c|}{ CYP4F2 (rs2108622): } \\
\hline AA & $8(6.4)$ & $19.13 \pm 5.46$ & 0.48 & $18(7.1)$ & $40.72 \pm 9.01$ & 0.93 \\
\hline AG & $41(32.8)$ & $20.85 \pm 6.51$ & & $94(37.2)$ & $41.38 \pm 11.79$ & \\
\hline GG & $76(60.8)$ & $21.80 \pm 6.82$ & & $141(55.7)$ & $40.89 \pm 10.45$ & \\
\hline \multicolumn{7}{|c|}{ CYP4F2 (rs1558139): } \\
\hline AA & $33(26.4)$ & $22.48 \pm 5.75$ & 0.43 & $55(21.7)$ & $40.38 \pm 11.19$ & 0.87 \\
\hline GA & $56(44.8)$ & $21.21 \pm 7.24$ & & $131(51.8)$ & $41.24 \pm 10.93$ & \\
\hline GG & $36(28.8)$ & $20.42 \pm 6.41$ & & $67(26.5)$ & $41.28 \pm 10.51$ & \\
\hline \multicolumn{7}{|c|}{ CYP4F2 (rs3093135): } \\
\hline AA & $64(51.2)$ & $22.88 \pm 6.30$ & 0.001 & $164(64.8)$ & $40.62 \pm 10.64$ & 0.67 \\
\hline AT & $52(41.6)$ & $20.56 \pm 6.51$ & & $75(29.6)$ & $41.85 \pm 11.65$ & \\
\hline TT & $9(7.2)$ & $14.67 \pm 5.07$ & & $14(5.5)$ & $42.07 \pm 8.86$ & \\
\hline \multicolumn{7}{|c|}{ CYP4F2 (rs2074902): } \\
\hline CC & $4(3.2)$ & $18.25 \pm 4.34$ & 0.22 & $14(5.5)$ & $42.07 \pm 8.86$ & 0.78 \\
\hline $\mathrm{TC}$ & $34(27.2)$ & $20.03 \pm 6.45$ & & $74(29.2)$ & $41.64 \pm 11.66$ & \\
\hline TT & $87(69.6)$ & $21.97 \pm 6.73$ & & $165(65.2)$ & $40.72 \pm 10.65$ & \\
\hline Total & $125(100.0)$ & $21.32 \pm 6.63$ & & $\begin{array}{l}253 \\
(100.0)\end{array}$ & $41.06 \pm 10.84$ & \\
\hline
\end{tabular}


Table 4. The effect of CYP4F2 rs3093135 TT variant on bleeding and thrombosis in dual antiplatelet therapy users after 6 months.

\begin{tabular}{|c|c|c|}
\hline Variable & Ticagrelor users, $\mathrm{n}(\%)$ & Clopidogrel users, n (\%) \\
\hline Bleeding $^{+}$ & $7(77.8)^{ \pm \uparrow}$ & 0 \\
\hline Recurrent myocardial infarction & 0 & $7(29.2)^{\text {รึ }}$ \\
\hline Stroke & 0 & $2(8.3)^{\pi}$ \\
\hline None & $2(22.2)^{\pi}$ & $15(62.5)^{ \pm \uparrow}$ \\
\hline Total & $9(100.0)$ & $24(100.0)$ \\
\hline \multicolumn{3}{|c|}{$\begin{array}{l}\text { All the patients experienced type } 1 \text { or } 2 \text { bleeding according to BARC classification. One patient had a type 3a bleeding. } \\
\text { 'Nosebleed, hematomas, blood in urine or gastrointestinal bleeding. } \\
\text { Distribution of CYP2C19*2 allele in presented patients: } \\
\text { *One patient had CYP2C19*1*2 variant. } \\
\text { sThree patients had CYP2C19*1*2 variant. } \\
\text { "Other patients had CYP2C19*1*1 variant. } \\
\text { BARC: Bleeding Academic Research Consortium. }\end{array}$} \\
\hline
\end{tabular}

inhibitors ( $\mathrm{n}=94)$ had significantly lower platelet aggregation values $\left(20.45 \pm 6.30 \%{ }^{\mathrm{agr}}\right)$ compared with the nonusers of ACE inhibitors $(23.97 \pm 7.00 \%$ agr $), p=0.01$. Concomitant $\beta$-blocker therapy $(\mathrm{n}=104)$ tended to lower platelet aggregation values $\left(20.83 \pm 6.34 \%{ }^{a g r}\right)$ in ticagrelor patients who used $\beta$-blockers, compared with nonusers of $\beta$-blockers $(23.76 \pm 7.62 \%$ agr, $\mathrm{p}=0.064)$. Study results demonstrated that a concomitant use of glimepiride $(\mathrm{n}=3)$ or metformin $(\mathrm{n}=37)$ in clopidogrel users significantly reduced the antiplatelet effect; platelet aggregation values in users of these drugs were higher $(\mathrm{p}<0.05)$ compared with nonusers $\left(57.67 \pm 6.11\right.$ and $45.19 \pm 11.51 \%^{\text {agr }}$ versus $40.86 \pm 10.74$ and $40.36 \pm 10.59 \%{ }^{\mathrm{agr}}$, respectively; Table 2).

The effect of CYP2C19 \& CYP4F2 genotypes on antiplatelet therapy

The lower platelet aggregation values in users of ticagrelor were associated with the CYP2C19 ${ }^{*}{ }^{*} 1$ (wild-type) variant $\left(20.30 \pm 6.42 \%{ }^{\mathrm{agr}}\right)$ rather than with the ${ }^{*} 1{ }^{*} 2$ variant $\left(23.22 \pm 7.08 \%{ }^{\mathrm{agr}}\right.$ ), $\mathrm{p}=0.028$ (Table 3 ). Users of clopidogrel with the ${ }^{*} 1^{*} 1$ variant had lower platelet aggregation values $(40.15 \pm 10.75 \%$ agr $)$ compared with the ${ }^{*} 1{ }^{*} 2$ heterozygous carriers $(46.53 \pm 9.80 \%$ agr $)$, $\mathrm{p}=0.001$. Moreover, significantly lower platelet aggregation values were detected in ticagrelor users who carried the CYP4F2 rs3093135 TT variant $\left(14.67 \pm 5.07 \mathrm{e}^{\mathrm{agr}}\right)$ versus the AA variant $(22.88 \pm 6.30 \%$ agr $), \mathrm{p}=0.0004$ or the AT variant $\left(20.56 \pm 6.51 \%{ }^{\mathrm{agr}}\right), \mathrm{p}=0.0126$ (Table 3 ).

\section{The impact of CYP4F2 rs3093135 TT variant on} bleeding \& thrombosis

It was determined that ticagrelor users who had the CYP4F2 rs3093135 TT variant had the lowest platelet aggregation values. Thus, a more detailed analysis showed that during the 6 months after initiation of antiplatelet therapy, only two out of nine patients who used ticagrelor (Table 4) had no bleeding events. One patient had a major type 3a (according to Bleeding Academic Research Consortium) gastrointestinal bleeding and required a blood transfusion. In 24 clopidogrel users, who were CYP4F2 rs3093135 TT carriers, bleeding was not reported. Recurrent MI and stenting occurred in $29.2 \%(n=7)$ of patients, stroke events were observed in $8.4 \%(n=2)$ of clopidogrel users (Table 4$)$.

\section{Discussion}

This study show, for the first time, that nonprocedural bleeding during ticagrelor therapy might be associated with the CYP4F2 rs3093135 TT variant. It is worth noting that carriers of the TT variant who were users of clopidogrel had a higher incidence of thrombotic events than noncarriers of this variant. During ticagrelor therapy, the carriers of the TT variant had lower platelet aggregation values compared with the AA and AT variant carriers; no such effect was observed in clopidogrel users. Additionally, it was determined that the antiplatelet effect of ticagrelor remained stable following initiation, and 4 weeks after treatment initiation. In the patients receiving clopidogrel, the antiplatelet effect reduced 4 weeks after treatment initiation. STEMI patients, who were users of clopidogrel, had higher platelet aggregation values than non-STEMI patients, 4 weeks after treatment initiation. Users of ticagrelor who were carriers of $C Y P 2 C 19{ }^{*} 1^{*} 1$ had lower platelet aggregation values than ${ }^{*} 1^{*} 2$ variant carriers. Concomitant use of ticagrelor and ACE inhibitors or $\beta$-blockers significantly increased the antiplatelet effect. We would like to underline that concomitant clopidogrel and antidiabetic drug use may significantly reduce therapeutic effect of clopidogrel.

Ticagrelor is known for its fast onset [26], and has been shown to have greater antiplatelet activity compared with clopidogrel [27]. The PLATO study showed that ticagrelor is a more effective drug for the 
prevention of MI, stroke or even death, compared with clopidogrel [2]. Similar results were reported by other studies [28,29]. However, its effect has not yet been proven for pre-PCI coronary reperfusion in a group of patients with acute STEMI following ticagrelor treatment [26]. We found higher platelet aggregation values and lower response to DAPT 4 weeks after treatment initiation in patients who had undergone PCI and stent implantation. Subsequently, further detailed analyses were performed. The patients were divided into two groups: clopidogrel or ticagrelor users. A total of twothirds of our patients received clopidogrel and a third received ticagrelor treatment. The antiplatelet effect of ticagrelor was higher, compared with clopidogrel, and remained stable following induction and 4 weeks after treatment initiation. The users of clopidogrel experienced a $13 \%$ reduction of the antiplatelet effect. Such a reduction in antiplatelet therapy might lead to higher risk of arterial thrombosis. A consistent therapeutic effect of ticagrelor in non-STEMI and STEMI patients has been described by various researchers [30,31]. Our results revealed that ticagrelor had the same antiplatelet effect in STEMI and non-STEMI patients. However, clopidogrel users who experienced STEMI had higher platelet aggregation values than non-STEMI patients after 4 weeks of antiplatelet therapy. Besides its antiplatelet effect, ticagrelor has a pleiotropic action and it increases plasma adenosine concentration by reducing recapturing of adenosine by red blood cells [32] Plasma adenosine facilitates arterial vasodilatation and may decrease injury caused by reperfusion [33,34]. It has been reported that ticagrelor prescription before reperfusion, after 4 weeks of antiplatelet treatment, improved animal (a rat) heart function [34].

Compared with clopidogrel, ticagrelor is a more effective drug for decreasing platelet aggregation and the prevention of arterial thrombosis, such as definite stent thrombosis; this is because it has a more beneficial mechanism of action than clopidogrel [29], and it does not require metabolic activation. On the other hand, it may cause more bleeding events $[2,28,35]$. Thus, one of the aims of our study was to identify genetic and nongenetic factors which may significantly affect the antiplatelet therapy of ticagrelor. Lower platelet aggregation values were observed in the ticagrelor users who concomitantly received additional ACE inhibitor $(p=0.01)$ or $\beta$-blocker $(\mathrm{p}=0.064)$ therapy. The results presented by Verdoia et al. were opposite to our study results [36]. They reported that only 26 of 195 patients who received ticagrelor and aspirin DAPT after stenting due to acute coronary syndromes were low responders, and they had high platelet reactivity between 1 and 3 months following initiation of treatment. The use of a $\beta$-blocker was also associated with lower response to ticagrelor therapy [36].
According to some researchers, higher dosages of aspirin during ticagrelor therapy may be required in diabetic patients [37]. Alexopoulos et al. suggest that diabetes mellitus and older age of a patient (older than 70 years) during clopidogrel therapy might be associated with higher platelet reactivity [38]. However, patient age and diabetes had no significant antiplatelet effect in our patient group treated with ticagrelor. A lower antiplatelet effect of clopidogrel therapy was observed in our diabetic patients, as well as among our users of glimepiride and metformin. Similarly, James et al. also found that diabetes had no significant effect on antiplatelet therapy in ticagrelor (in comparison with clopidogrel) treated patients [39].

CYP2C19 variants are known to be the major genetic factors that determine the therapeutic effect of clopidogrel $[10,11]$. Our results are in line with this statement as the lowest platelet aggregation, and strongest antiplatelet effect, was found in ${ }^{*} 1^{*} 1$ carriers versus ${ }^{*} 1^{*} 2$ and ${ }^{*} 2{ }^{*} 2$ carriers. It is important to note that users of ticagrelor who were ${ }^{*} 1^{*} 1$ variant carriers had lower platelet aggregation than ${ }^{*} 1 * 2$ variant carriers. A possible explanation for this might be the altered metabolism of other factors involved in vascular homeostasis. CYP2C19 is involved in metabolism of arachidonic acid derivatives (19-HETE) [40]. Arachidonic acid derivatives may act on inflammation, and it is well known that they may have a significant role in platelet aggregation [25]. Moreover, our previous studies demonstrated that CYP4F2 may affect platelet aggregation [25] and may impact stent thrombosis in patients who have undergone PCI and stent implantation [41]. Thus, after analysis of the currently available literature, we decided to investigate the prevalence of genotypes of CYP4F2 (rs2108622, rs1558139, rs3093135 and rs2074902) in our patient population. Significantly lower platelet aggregation values were found in ticagrelor users who were rs3093135 TT variant carriers, as compared with AT or AA variant carriers. No such effect was found in clopidogrel users. Furthermore, a more in-depth examination of the patients with the CYP4F2 rs3093135 TT variant was performed 6 months after initiation of antiplatelet therapy. Our results showed that only $22 \%$ of these patients who used ticagrelor had no bleeding events, such as nose and gastrointestinal bleeding, hematomas or blood in urine; one patient had a major gastrointestinal bleeding which led to hospitalization and blood transfusion. The bleeding events were not observed in clopidogrel users, but these patients did experience arterial thrombotic events such as recurrent MI and stenting (30\%) and stroke (8\%). The PLATO study also demonstrated that ticagrelor use was associated with a higher prevalence of nonprocedural bleeding 
events after PCI [2]. The observed variants of CYP4F2 had no significant impact on bleeding in our clopidogrel-treated patients. Finally, we would like to hypothesize that the CYP4F2 rs3093135 TT variant might be associated not only with lower platelet aggregation values, but it may also have a significant influence on nonprocedural bleeding due to ticagrelor use.

This study has some limitations. Only the patients, who matched inclusion criteria as described in the 'Materials \& methods' section, were included into the further study. We did not evaluate the impact of such factors as platelet turnover or obesity; thus, clinical factors may not be sufficiently reflected in our study. Also, we did not analyze the impact of $C Y P 2 C 19^{*} 3$ or * 17 allele, ATP-binding cassette transporter or CYP3A4 variant. In addition, the presented hemostasis complications in DAPT users after 6 months of treatment are only for CYP4F2 rs3093135 TT variant carriers. Thus, further large-scale studies in the future will be required.

\section{Conclusion \& future perspective}

Results of the current study showed that CYP4F2 rs3093135 TT variant carriers, compared with AA and AT variant carriers, had a higher antiplatelet effect of ticagrelor, and had more frequent nonprocedural bleeding during ticagrelor therapy. A more stable and higher antiplatelet effect was observed in ticagrelor users compared with clopidogrel users, regardless of whether they had STEMI or non-STEMI before induction of antiplatelet therapy. Additionally, our results showed that $C Y P 2 C 19^{*} 1^{*} 1$ variant carriers had a higher antiplatelet effect than mutant $\left({ }^{*} 2\right)$ allele carriers, regardless of whether they were taking clopidogrel or ticagrelor. Concomitant use of ticagrelor and ACE inhibitors or $\beta$-blockers increased the antiplatelet effect. Users of clopidogrel and antidiabetic drugs also had a lower antiplatelet effect than nonusers.

Data from this study may help to improve understanding and explain the pharmacogenomics of ticagrelor; this can inform future studies in this field. In the near future, identification of patients with the CYP4F2 rs3093135 TT variant might significantly reduce bleeding events related to ticagrelor use. In 5-10 years, findings from the present study may help to inform more detailed studies of antiplatelet drug dosage, and may contribute to ensuring safe and effective dosage of ticagrelor in those patients who have a higher risk of misdosage.

\section{Financial \& competing interests disclosure}

These studies were funded by a grant (grant no. SEN-09/2015) from the Research Council of Lithuania. The authors have no other relevant affiliations or financial involvement with any organization or entity with a financial interest in or financial conflict with the subject matter or materials discussed in the manuscript apart from those disclosed.

No writing assistance was utilized in the production of this manuscript.

\section{Ethical conduct of research}

All the procedures used in this study were approved by Kaunas Regional Ethics Committee for Biomedical Research, Lithuania, in compliance with ethical standards (permission number BE2-30) and the World Medical Association Declaration of Helsinki on Ethical Principles for Medical Research Involving Human Subjects.

\section{Open access}

This work is licensed under the Attribution-NonCommercialNoDerivatives 4.0 Unported License. To view a copy of this license, visit http://creativecommons.org/licenses/by-nc-nd/4.0/

\section{Summary points}

- The newer generation antiplatelet drug ticagrelor demonstrates a faster onset and more potent inhibition, but can cause bleeding events more frequently than clopidogrel.

- Currently, there are no genetic polymorphisms identified which may explain the antiplatelet activity of ticagrelor.

- Thus, the aim of this study was to determine clinically significant factors which may alter the effect of dual antiplatelet therapy (aspirin and ticagrelor or clopidogrel) in patients who had undergone percutaneous coronary intervention and stent implantation.

- Ticagrelor users had lower platelet aggregation values than users of clopidogrel following induction of treatment, and after 4 weeks of treatment. Ticagrelor users had consistent platelet aggregation values after initiation of treatment, and after 4 weeks of treatment.

- Users of clopidogrel with ST-elevation myocardial infarction had higher platelet aggregation values than non-ST-elevation myocardial infarction patients. No such effect was observed in ticagrelor users.

- The lower platelet aggregation values were associated with the CYP2C19*1*1 (wild-type) variant.

- Lower platelet aggregation values were detected in ticagrelor users who carried the CYP4F2 rs3093135 TT variant $(14.67 \pm 5.07 \%$ arr $)$ versus the AA variant $(22.88 \pm 6.30 \%$ arr $), p=0.0004$, or the AT variant $(20.56 \pm$ $\left.6.51 \%{ }^{\mathrm{agr}}\right), \mathrm{p}=0.0126$.

- Patients who are carriers of the TT variant and who were treated with ticagrelor experienced bleeding events more frequently than clopidogrel users. 


\section{References}

1 Wiviott SD, Braunwald E, McCabe $\mathrm{CH}$ et al. Prasugrel versus clopidogrel in patients with acute coronary syndromes. N. Engl. J. Med. 357(20), 2001-2015 (2007).

2 Wallentin L, Becker RC, Budaj A et al. Ticagrelor versus clopidogrel in patients with acute coronary syndromes. N. Engl. J. Med. 361(11), 1045-1057 (2009).

3 Steg PG, James SK, Atar D et al. ESC Guidelines for the management of acute myocardial infarction in patients presenting with ST-segment elevation. Eur. Heart J. 33(20), 2569-2619 (2012).

4 Hamm CW, Bassand JP, Agewall S et al. ESC Guidelines for the management of acute coronary syndromes in patients presenting without persistent ST-segment elevation: The Task Force for the Management of Acute Coronary Syndromes (ACS) in patients presenting without persistent ST-segment elevation of the European Society of Cardiology (ESC). Eur. Heart J. 32(23), 2999-3054 (2011).

5 Windecker S, Kolh P, Alfonso F et al. 2014 ESC/EACTS Guidelines on myocardial revascularization: the Task Force on Myocardial Revascularization of the European Society of Cardiology (ESC) and the European Association for CardioThoracic Surgery (EACTS) developed with the special contribution of the European Association of Percutaneous Cardiovascular Interventions (EAPCI). Eur. Heart J. 35(37), 2541-2619 (2014).

6 Sahlén A, Varenhorst C, Lagerqvist B et al. Outcomes in patients treated with ticagrelor or clopidogrel after acute myocardial infarction: experiences from SWEDEHEART registry. Eur. Heart J. 37(44), 3335-3342 (2016).

7 Hagihara K, Kazui M, Kurihara A et al. A possible mechanism for the differences in efficiency and variability of active metabolite formation from thienopyridine antiplatelet agents, prasugrel and clopidogrel. Drug Metab. Dispos. 37(11), 2145-2152 (2009).

8 Kazui M, Nishiya Y, Ishizuka T et al. Identification of the human cytochrome P450 enzymes involved in the two oxidative steps in the bioactivation of clopidogrel to its pharmacologically active metabolite. Drug Metab. Dispos. 38(1), 92-99 (2010).

9 Tang M, Mukundan M, Yang J et al. Antiplatelet agents aspirin and clopidogrel are hydrolyzed by distinct carboxylesterases, and clopidogrel is transesterificated in the presence of ethyl alcohol. J. Pharmacol. Exp. Ther. 319(3), 1467-1476 (2006).

10 Pratt V, McLeod H, Dean L et al. Medical Genetics Summaries. National Center for Biotechnology Information, MD, USA (2015).

11 Gilard M, Arnaud B, Cornily JC et al. Influence of omeprazole on the antiplatelet action of clopidogrel associated with aspirin: the randomized, double-blind OCLA (Omeprazole Clopidogrel Aspirin) study. J. Am. Coll. Cardiol. 51(3), 256-260 (2008).

12 von Beckerath N, Taubert D, Pogatsa-Murray G et al. A patient with stent thrombosis, clopidogrel-resistance and failure to metabolize clopidogrel to its active metabolite. Thromb. Haemost. 93(4), 789-791 (2005).
13 Simon T, Verstuyft C, Mary-Krause M et al. Genetic determinants of response to clopidogrel and cardiovascular events. N. Engl. J. Med. 360(4), 363-375 (2009).

14 Bouman HJ, Schömig E, van Werkum JW et al. Paraoxonase-1 is a major determinant of clopidogrel efficacy. Nat. Med. 17(1), 110-116 (2011).

15 Sibbing D, Koch W, Massberg S et al. No association of paraoxonase-1 q192r genotypes with platelet response to clopidogrel and risk of stent thrombosis after coronary stenting. Eur. Heart J. 32, 1605-1613 (2011).

16 Lewis JP, Fisch AS, Ryan K et al. Paraoxonase 1 (PON1) gene variants are not associated with clopidogrel response. Clin. Pharmacol. Ther. 90, 568-574 (2011).

17 Hulot JS, Collet JP, Cayla G et al. CYP2C19 but not PON1 genetic variants influence clopidogrel pharmacokinetics, pharmacodynamics, and clinical efficacy in post-myocardial infarction patients. Circ. Cardiovasc. Interv. 4, 422-428 (2011).

18 Paré G, Ross S, Mehta SR et al. Effect of PON1 Q192R genetic polymorphism on clopidogrel efficacy and cardiovascular events in the Clopidogrel in the Unstable Angina to Prevent Recurrent Events trial and the Atrial Fibrillation Clopidogrel Trial with Irbesartan for Prevention of Vascular Events. Circ. Cardiovasc. Genet. 5(2), 250-256 (2012).

19 Frelinger AL 3rd, Bhatt DL, Lee RD et al. Clopidogrel pharmacokinetics and pharmacodynamics vary widely despite exclusion or control of polymorphisms (CYP2C19, $A B C B 1, P O N 1$ ), noncompliance, diet, smoking, comedications (including proton pump inhibitors), and pre-existent variability in platelet function. J. Am. Coll. Cardiol. 61(8), 872-879 (2013).

20 Gerrits AJ, Jakubowski JA, Sugidachi A, Michelson AD, Frelinger AL 3rd. Incomplete reversibility of platelet inhibition following prolonged exposure to ticagrelor. J. Thromb. Haemost. 15(5), 858-867 (2017).

21 Pourdjabbar A, Hibbert B, Chong AY et al. A pharmacodynamic analysis for the co-administration of inducers of CYP3A with ticagrelor: a cautionary tale in managing patients with acute coronary syndromes. Int. J. Cardiol. 214, 423-425 (2016).

22 Varenhorst C, Eriksson N, Johansson $\AA$ et al. Effect of genetic variations on ticagrelor plasma levels and clinical outcomes. Eur. Heart J. 36(29), 1901-1912 (2015).

23 Li M, Hu Y, Li H et al. No effect of SLCO1B1 and CYP3A4/5 polymorphisms on the pharmacokinetics and pharmacodynamics of ticagrelor in healthy chinese male subjects. Biol. Pharm. Bull. 40(1), 88-96 (2017).

24 Mehran R, Rao SV, Bhatt DL et al. Standardized bleeding definitions for cardiovascular clinical trials: a consensus report from the Bleeding Academic Research Consortium. Circulation 123(23), 2736-2747 (2011).

25 Tatarunas V, Jankauskiene L, Kupstyte $\mathrm{N}$ et al. The role of clinical parameters and of CYP2C19 G681 and CYP4F2 G1347A polymorphisms on platelet reactivity during dual antiplatelet therapy. Blood Coagul. Fibrinolysis 25(4), 369-374 (2014).

26 Montalescot G, van 't Hof AW, Lapostolle F et al. Prehospital ticagrelor in ST-segment elevation myocardial infarction. N. Engl. J. Med. 371(11), 1016-1027 (2014). 
27 Storey RF, Angiolillo DJ, Patil SB et al. Inhibitory effects of ticagrelor compared with clopidogrel on platelet function in patients with acute coronary syndromes: the PLATO (PLATelet inhibition and patient Outcomes) PLATELET substudy. J. Am. Coll. Cardiol. 56(18), 1456-1462 (2010).

en A, Varenhorst C, Lagerqvist B et al. Outcomes in patients treated with ticagrelor or clopidogrel after acute myocardial infarction: experiences from SWEDEHEART registry. Eur. Heart J. 37(44), 3335-3342 (2016).

29 Velders MA, Abtan J, Angiolillo DJ et al. Safety and efficacy of ticagrelor and clopidogrel in primary percutaneous coronary intervention. Heart 102(8), 617-625 (2016).

Lindholm D, Varenhorst C, Cannon CP et al. Ticagrelor vs. clopidogrel in patients with non-ST-elevation acute coronary syndrome with or without revascularization: results from the PLATO trial. Eur. Heart J. 35(31), 2083-2093 (2014).

31 Steg PG, James S, Harrington RA et al. Ticagrelor versus clopidogrel in patients with ST-elevation acute coronary syndromes intended for reperfusion with primary percutaneous coronary intervention: a Platelet Inhibition and Patient Outcomes (PLATO) trial subgroup analysis. Circulation 122(21), 2131-2141 (2010).

32 Bonello L, Laine M, Kipson $\mathrm{N}$ et al. Ticagrelor increases adenosine plasma concentration in patients with an acute coronary syndrome. J. Am. Coll. Cardiol. 63(9), 872-877 (2014).

33 Li XY, Wang QB, Xue Y, Chen JH, Lv QZ. Ticagrelor increased adenosine and cyclic adenosine monophosphate plasma concentration compared with clopidogrel in acute coronary syndromes patients. Basic Clin. Pharmacol. Toxicol. 120(6), 610-614 (2017).

34 Ye Y, Birnbaum GD, Perez-Polo JR, Nanhwan MK, Nylander S, Birnbaum Y. Ticagrelor protects the heart against reperfusion injury and improves remodeling after myocardial infarction. Arterioscler. Thromb. Vasc. Biol. 35(8), 1805-1814 (2015).

Alexopoulos D, Xanthopoulou I, Deftereos S et al. Contemporary antiplatelet treatment in acute coronary syndrome patients undergoing percutaneous coronary intervention: 1 year outcomes from the GReek AntiPlatElet (GRAPE) Registry. J. Thromb. Haemost. 14(6), 1146-1154 (2016).

36 Verdoia M, Sartori C, Pergolini P et al. Prevalence and predictors of high-on treatment platelet reactivity with ticagrelor in ACS patients undergoing stent implantation. Vascul. Pharmacol. 77, 48-53 (2016).

DiNicolantonio JJ, Serebruany VL. Challenging the FDA black box warning for high aspirin dose with ticagrelor in patients with diabetes. Diabetes 62 (3), 669-671 (2013).

38 Alexopoulos D, Xanthopoulou I, Storey RF et al. Platelet reactivity during ticagrelor maintenance therapy: a patientlevel data meta-analysis. Am. Heart J. 168(4), 530-536 (2014).

39 James S, Angiolillo DJ, Cornel JH et al. Ticagrelor vs. clopidogrel in patients with acute coronary syndromes and diabetes: a substudy from the PLATelet inhibition and patient Outcomes (PLATO) trial. Eur. Heart J. 31(24), 3006-3016 (2010).

40 Knights KM, Rowland A, Miners JO. Renal drug metabolism in humans: the potential for drug-endobiotic interactions involving cytochrome P450 (CYP) and UDP-glucuronosyltransferase (UGT). Br. J. Clin. Pharmacol. 76(4), 587-602 (2013).

41 Kupstyte N, Zaliunas R, Tatarunas V et al. Effect of clinical factors and gene polymorphism of $C Y P 2 C 19^{*} 2$, * 17 and $C Y P 4 F 2 * 3$ on early stent thrombosis. Pharmacogenomics 16(3), 181-189 (2015). 